\title{
Reproductive experience and opioid regulation of luteinizing hormone release in female rats
}

\author{
R. M. Hopwood, P. E. Mann and R. S. Bridges* \\ Department of Biomedical Sciences, Tufts University School of Veterinary Medicine, North Grafton, MA 01536, USA
}

\begin{abstract}
The objective of the present study was to determine whether reproductive experience that produces shifts in opioid regulation of prolactin secretion and behavioural functions also alters opioid regulation of LH during the oestrous cycle or lactation. In Expt 1 the effect of naloxone administration (i.v.) on LH was compared between agematched, nulliparous and primiparous, catheterized female rats on dioestrus II. In Expt 2 , the effects of multiple reproductive experiences on opiate control of $\mathrm{LH}$ were investigated using cyclic, nulliparous and multiparous (three litters) rats. In both experiments, no differences in naloxone-stimulated LH release were found between groups even though multiple reproductive experiences resulted in the prolongation of oestrous cyclicity. In Expt 3, day 8 lactating primiparous rats were administered 2, 5, 10 or $25 \mathrm{mg}$ naloxone $\mathrm{kg}^{-1}$ i.v. The three lowest naloxone doses, but not the $25 \mathrm{mg} \mathrm{kg}^{-1}$ dose, significantly increased LH concentrations. The possible effects of prior reproductive experience on opioid control of $\mathrm{LH}$ during lactation were then investigated. Naloxone at $0.5 \mathrm{mg} \mathrm{kg}^{-1}$, but not at $2 \mathrm{mg} \mathrm{kg}^{-1}$ or $10 \mathrm{mg} \mathrm{kg}^{-1}$, stimulated a significantly greater rise in LH in multiparous (two litters) than in primiparous females. Overall, these data indicate that while modest differences were found in naloxoneinduced $\mathrm{LH}$ responses between multiparous and primiparous animals during lactation, reproductive experience did not significantly alter opioid regulation of $\mathrm{LH}$ during subsequent oestrous cycles at the naloxone doses examined. Hence, the effects of reproductive experience on opioid regulation of $\mathrm{LH}$ are less pronounced than those previously found for opioid regulation of prolactin and behaviour.
\end{abstract}

\section{Introduction}

The endogenous opioid peptides (EOP) appear to influence reproductive function by tonic inhibition of hypothalamic GnRH secretion at all stages of the oestrous cycle (Gabriel et al., 1983). When naloxone, a non-specific opioid receptor antagonist, is administered to rats, LH is no longer inhibited by the EOP resulting in an increase in GnRH release from the hypothalamus and a subsequent pituitary release of LH. However, marked age and sex differences in the LH response of rats to naloxone have been reported, suggesting a more complex influence of the EOP on GnRH secretion (Blank et al., 1979; Cicero et al., 1980; Chiba et al., 1997).

In contrast to the inhibitory effects of opioids on $\mathrm{LH}$, EOP stimulate the release of prolactin (Selmanoff and Gregerson, 1986). Opioids, such as $\beta$-endorphin, are thought to increase prolactin concentrations during lactation and possibly during the prepartum period (Dondi et al., 1991). Recent studies have shown that reproductive experience alters the female's sensitivity to opioid regulation of prolactin secretion as well as maternal behaviour (Kinsley and

${ }^{*}$ Correspondence.

Received 21 November 1997.
Bridges, 1988). When the effects of reproductive experience on maternal behaviour in rats was evaluated after central infusion of $\beta$-endorphin into the medial preoptic area (MPOA) (Mann and Bridges, 1992), an area of the brain that is responsible for the induction and maintenance of maternal behaviour (Numan, 1990), it was found that multiparous lactating rats were less sensitive than age-matched, primiparous lactating rats to the disruptive effects of $\beta$-endorphin administration on maternal behaviour. In addition, multiparous lactating rats had significantly lower concentrations of prolactin after suckling than did primiparous, lactating rats (Mann and Bridges, 1992). Thus, in general, multiparous rats appeared to be less affected by opioid administration than were age-matched, primiparous rats.

In the present study, the role of opioids in $\mathrm{LH}$ regulation was investigated using a number of experimental approaches. Unpublished findings from our laboratory indicate that the proestrous $\mathrm{LH}$ surge is dampened in cyclic primiparous rats compared with the surge in age-matched, nulliparous animals (R. S. Bridges and L. C. Vecellio, unpublished data). As opioids appear to inhibit GnRH, and thus LH, secretion in cyclic animals (Blank et al., 1986; Weiner et al., 1988), the aim was to delineate the possible 
involvement of opiates in LH release in reproductively experienced animals. In the first experiment the effects of the opiate antagonist naloxone on LH release was examined in cyclic, dioestrous II, nulliparous and primiparous female rats. On the basis of findings of earlier studies (Kinsley and Bridges, 1988; Mann and Bridges, 1992), we hypothesized that primiparous female rats would be less sensitive to the effects of naloxone than would nulliparous females. Thus, the rise in LH would be greater in nulliparous females. The possibility was also investigated that additional reproductive experience (more than two births) might alter the sensitivity of the hypothalamus to opioids in the regulation of $\mathrm{LH}$ by comparing the pattern of $\mathrm{LH}$ release on dioestrus II in age-matched cyclic, nulliparous and multiparous females that had raised three litters.

A final study examined the possible effects of reproductive experience on opioid regulation of $\mathrm{LH}$ secretion during lactation. Suckling both increases the concentrations of EOP (Selmanoff and Gregerson, 1986) and inhibits LH release (Smith and Neill, 1977). Therefore, a naloxone-LH dose-response curve was established in primiparous, lactating rats using four naloxone doses administered i.v. Afterwards the effects of naloxone administration during lactation in age-matched, primiparous and multiparous females were investigated to determine whether $\mathrm{LH}$ release was diminished in multiparous, lactating animals, reflecting a decreased sensitivity to opioid peptides.

\section{Materials and Methods}

\section{Animals}

Nulliparous female Sprague-Dawley [Crl:CD(SD)BR] virus-free rats $(226-250 \mathrm{~g})$ were purchased from Charles River Laboratories, Inc. (Kingston, NY) and housed upon their arrival in our animal facilities in $45 \mathrm{~cm} \times 25 \mathrm{~cm} \times 20 \mathrm{~cm}$ opaque polypropylene cages. Animals were maintained in temperature $\left(21-25^{\circ} \mathrm{C}\right)$ - and light $(14 \mathrm{~h}$ light: $10 \mathrm{~h}$ dark cycle; lights on at 06:00 h)-controlled rooms and provided with food (Purina Rat Chow, Ralston-Purina Co., St Louis, MO) and water ad libitum. Female rats were initially housed two per cage for a minimum of one week at which time they were separated into experimental groups. Animals used in this study were maintained in accordance with the guidelines of the Division of Laboratory Animal Medicine at Tufts University School of Veterinary Medicine, which follow the guidelines for animal care prepared by the Committee on Care and Use of Laboratory Animal Resources, National Research Council.

\section{Experiment 1}

Experiment 1 consisted of two parts. In the first part, seventy-five- to ninety-day-old nulliparous female rats were single-housed, and vaginal lavages were performed daily until these females demonstrated two consecutive 4 or 5 day oestrous cycles. On the day of vaginal oestrus, intra-atrial catheters were inserted via the right jugular vein under
Metofane (Mallinckrodt, Phillipsburg, NJ) anaesthesia. The following day catheters were flushed with heparinized saline $\left(50 \mathrm{iu} \mathrm{ml} \mathrm{m}^{-1}\right)$. Blood samples $(0.5 \mathrm{ml})$ were taken using heparinized syringes on the day of dioestrus II starting between 09:00 and 11:00 h. Samples were taken at -10, 0, 10, $20,30,45,60$ and $120 \mathrm{~min}$. At the zero time point rats were injected via the intra-atrial catheters with one of the three treatments: vehicle (saline; $n=7$ ), naloxone $\left(1 \mathrm{mg} \mathrm{kg}^{-1} ; n=7\right)$ or naloxone $\left(10 \mathrm{mg} \mathrm{kg}^{-1} ; n=7\right)$. Blood samples were centrifuged at $16000 \mathrm{~g}$ for $1 \mathrm{~min}$ and plasma samples were collected and stored at $-20^{\circ} \mathrm{C}$ until assayed for $\mathrm{LH}$ by radioimmunoassay. Throughout each experiment when multiple samples (more than four) were collected, red blood cells from individual samples were resuspended in approximately $0.5 \mathrm{ml}$ of physiological saline. The cell suspensions were returned to each subject after the subsequent blood sampling to maintain blood volume and haematocrit count. Cells from the final blood sample during each collection period were not returned to the experimental animals.

Rats in the second part of this experiment were separated into two groups. One group of nulliparous females was double-housed and remained unmated, while the other group was mated with males from our colony and housed individually before parturition. On the day after parturition the litters were culled to six pups and were raised to weaning on day 21 postpartum. After weaning the young, vaginal lavages were performed daily on primiparous rats, which were paired with the age-matched nulliparous females, until they demonstrated two consecutive 4 or 5 day oestrous cycles. As described previously, intra-atrial catheters were inserted on the day of vaginal oestrus and the following day catheters were rinsed with heparinized saline. Blood samples $(0.5 \mathrm{ml})$ were collected on the day of dioestrus II starting between 09:00 and 11:00 h. Samples were taken at -10, 10, 20, 30 and $60 \mathrm{~min}$. At the zero time point, rats were injected via the intra-atrial catheter with either vehicle (saline; primiparous $n=6$, nulliparous $n=5)$ or naloxone $\left(1 \mathrm{mg} \mathrm{kg}^{-1}\right.$; primiparous $n=12$, nulliparous $n=9$ ). Blood samples were processed as previously noted.

\section{Experiment 2}

Rats in Expt 2 were separated into two age-matched groups. One group remained nulliparous, while rats in the other group (multiparous, three litters) were mated to males from our colony at three separate times. Litters were culled to six pups the day after each parturition and raised to weaning on day 21 postpartum. After weaning the third litter at approximately eight months of age, vaginal lavages were taken daily from multiparous females together with the agematched, nulliparous females until they demonstrated two consecutive 4 or 5 day oestrous cycles. On the day of vaginal oestrus, intra-atrial catheters were inserted as previously described. The following day, catheters were flushed with heparinized saline $\left(50 \mathrm{iu} \mathrm{ml} \mathrm{m}^{-1}\right)$. Blood samples $(0.6-0.7 \mathrm{ml})$ were collected on the day of dioestrus II starting between 09:00 and 10:30 $\mathrm{h}$ at the following time points: $-10,10,20,30$, and $60 \mathrm{~min}$. At the zero time point, rats were injected i.v. with naloxone ( $1 \mathrm{mg} \mathrm{kg}^{-1}$; multiparous $n=17$, nulliparous $n=6$ ). 
Catheters were kept patent on non-sampling days by flushing with heparinized saline. Blood samples were again collected on the day of dioestrus II in the subsequent oestrous cycle starting between 09:00 and 10:30 h. The sampling time points were the same as in the prior cycle; however, the rats were injected i.v. at the zero time point with $0.5 \mathrm{mg}$ naloxone $\mathrm{kg}^{-1}$ (multiparous $n=16$, nulliparous $n=4)$. The dosage of naloxone was reduced in the subsequent oestrous cycle to address the possibility that the $1 \mathrm{mg} \mathrm{kg}^{-1}$ dose may have produced a maximum response in both the nulliparous and multiparous rats. Blood samples were processed and assayed for LH as previously described.

\section{Experiment 3}

Rats in part A of Expt 3 were mated to males from our colony and randomly assigned to one of four groups. The day after parturition the litters were culled to six pups. On day 6 of lactation intra-atrial catheters were inserted via the right jugular vein into these primiparous rats. On day 7 catheters were flushed with heparinized saline $\left(50 \mathrm{iu} \mathrm{ml} \mathrm{m}^{-1}\right)$.

Between 08:00 and 09:00 h on day 8 of lactation, pups were removed and sampling of these primiparous rats began between 12:00 and 13:00 h, $4 \mathrm{~h}$ after pup removal. Blood samples were taken at $-10,0,10,20,30$, and $60 \mathrm{~min}$. At the zero time point, separate groups of rats were injected i.v. with either $2(n=8), 5(n=5), 10(n=8)$, or $25(n=5) \mathrm{mg}$ naloxone $\mathrm{kg}^{-1}$. Blood samples were processed and assayed for LH determinations.

Two groups of rats were used in part B of Expt 3. One group initially was unmated, while the other was mated to males from our colony. The day after parturition litters were culled to six pups and subsequently raised to day 21 postpartum. Seven to ten days after weaning, these primiparous rats along with the initially unmated group were mated to males in our colony to produce multiparous and primiparous females, respectively. Again, on the day after parturition, litters were culled to six pups. As in the first part of this experiment, females received intra-atrial catheters on day 6 of lactation. On day 7, catheters were flushed with heparinized saline. Between 08:00 and 09:00 h on day 8 of lactation, pups were removed and sampling began between 12:00 and 13:00 h, $4 \mathrm{~h}$ after pup removal. Blood samples were taken at $0,10,20$ and $30 \mathrm{~min}$ based on results of the first part of the experiment. At the zero time point, rats were injected i.v. with $2 \mathrm{mg} \mathrm{kg}^{-1}$ (multiparous $n=$ 19 , primiparous $n=11$ ) naloxone. On day 9, catheters were again flushed with heparinized saline. Between 08:00 and 09:00 h on day 10 of lactation, pups were removed and sampling began between 12:00 and 13:00 h. Blood samples were taken at the same time points, but rats were separated into two groups and administered either 0.5 (multiparous $n=7$, primiparous $n=5$ ) or 10 (multiparous $n=10$, primiparous $n=6$ ) $\mathrm{mg}$ naloxone $\mathrm{kg}^{-1}$ i.v. at the zero time point. The dosage of naloxone was both decreased and increased to establish whether the initial $2 \mathrm{mg} \mathrm{kg}^{-1}$ i.v. dose was producing a maximal response in both the multiparous and primiparous rats. Blood samples were processed as previously described and plasma assayed for LH content.

\section{Radioimmunoassay}

LH was measured by radioimmunoassay using the National Hormone Pituitary Program LH kit. This assay has previously been validated in our laboratory (Rubin et al., 1985). The LH antibody was NIDDK-anti-rLH-S-11. The reference preparation was NIDDK-rLH-RP-3. Iodinated (I125) LH was obtained from Hazelton Washington Inc. (Vienna, VA). The assay sensitivity ranged from 10 to $20 \mathrm{pg}$ per tube and the interassay and intra-assay coefficients of variation were $8.9 \%$ and $4.9 \%$, respectively.

\section{Statistical analyses}

Statistical analyses of the LH data were performed using an analysis of variance (ANOVA). Multiple comparisons were performed using the least significant difference test. Nonparametric data were analysed using the Fisher's exact probability test. Since in Expt 3 baseline LH concentrations were significantly different between the primiparous and multiparous groups, difference scores were calculated. This computation included subtraction of baseline $\mathrm{LH}$ values at each time point before performing an ANOVA.

\section{Results}

\section{Experiment 1}

The aim of the first part of this experiment was to establish a dose of the opiate antagonist naloxone that would effectively stimulate $\mathrm{LH}$ release in nulliparous rats on dioestrus II. There was a significant main effect of group $(\mathrm{F} 2,126=5.67, P<0.05)$ and time $(\mathrm{F} 7,126=2.61, P<0.01)$. In addition, there was a significant interaction between group and time $(\mathrm{F} 14,126=2.47, P<0.01)$. Naloxone treatment at 1 $\mathrm{mg} \mathrm{kg}^{-1}$ i.v. resulted in high $\mathrm{LH}$ values which differed significantly from vehicle at 10, 20, 45 and $60 \mathrm{~min}$. Plasma LH concentrations increased from about $0.4 \mathrm{ng} \mathrm{ml}^{-1}$ to $0.8 \mathrm{ng} \mathrm{ml}^{-1}$ at $10 \mathrm{~min}$. LH concentrations after the $10 \mathrm{mg} \mathrm{kg}^{-1}$ dose of naloxone differed significantly at 10,45 and $60 \mathrm{~min}$, rising from $0.5 \mathrm{ng} \mathrm{ml}^{-1}$ to $0.8 \mathrm{ng} \mathrm{ml}^{-1}$ at 10 and $20 \mathrm{~min}$. LH values in vehicle-treated animals decreased between 30 and $45 \mathrm{~min}(P$ $<0.05)$ and returned to baseline concentrations thereafter. The group differences present at the $45 \mathrm{~min}$ and possibly the $60 \mathrm{~min}$ collection points may have been the result of low concentrations of $\mathrm{LH}$ in the vehicle-treated controls. LH concentrations in naloxone-treated animals at these times remained fairly constant or tended to decline slightly.

The goal of the second part of Expt 1 was to compare the $\mathrm{LH}$ responses to naloxone on dioestrus II between agematched, nulliparous and primiparous females (Fig. 1). With the $1 \mathrm{mg} \mathrm{kg}^{-1}$ dose, significant main effects of drug (F1,28 = 23.83, $P<0.001)$ and time $(\mathrm{F} 4,112=10.73, P<0.001)$ were found. Neither the two-way interaction between group and drug $(\mathrm{F} 1,28=0.37, P>0.05)$ nor group and time $(F 4,112=$ $0.68, P>0.05)$ were significant. However, the two-way interaction between time and drug was significant $(F 4,112=$ $8.08, P<0.001)$. There were no significant differences between 


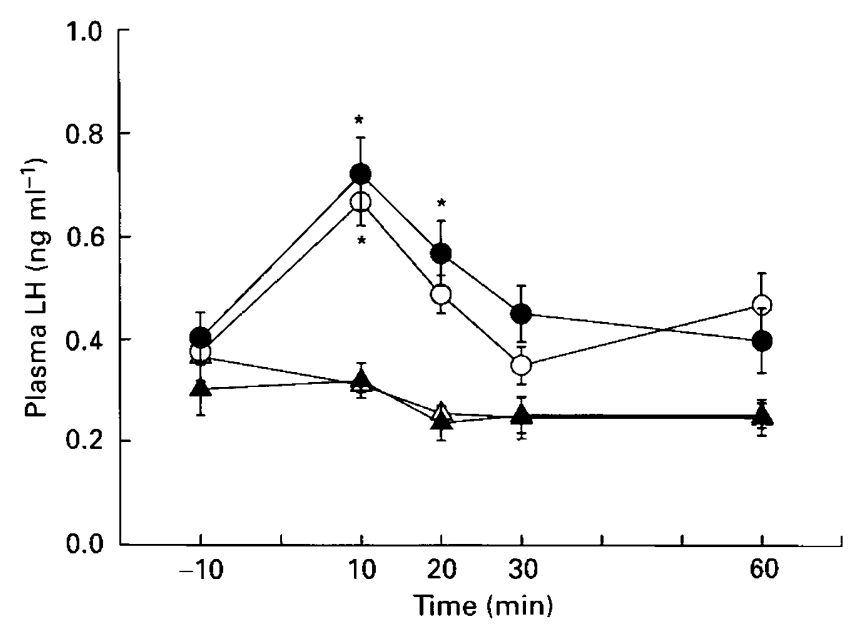

Fig. 1. Comparison of plasma concentrations of $\mathrm{LH}$ after administration of naloxone $\left(1 \mathrm{mg} \mathrm{kg}^{-1}\right.$ i.v.) or vehicle (saline) to nulliparous and primiparous female rats on dioestrus II. (- primiparous/naloxone $(n=12) ; \bigcirc$ nulliparous/naloxone $(n=9)$; $\Delta$ primiparous/vehicle $(n=6) ; \triangle$ nulliparous/vehicle $(n=5))$. There were no significant differences between the nulliparous and primiparous females. Naloxone treatment resulted in significant increases in LH in the nulliparous and primiparous animals within $10 \mathrm{~min}$ of naloxone administration. ${ }^{*} P<0.05$ compared with baseline values.

nulliparous and primiparous groups after either vehicle or naloxone treatments (Fig.1), although the groups administered naloxone had significantly higher LH concentrations than did vehicle-treated animals after naloxone administration $(P<0.05-0.001)$.

\section{Experiment 2}

The aim of this experiment was to compare circulating LH concentrations collected on dioestrus II between agematched nulliparous and multiparous (three litters) female rats after naloxone $\left(1 \mathrm{mg} \mathrm{kg}^{-1}\right)$ treatment. As shown in Fig. 2a, there was a significant main effect of time $(F 4,84=17.29$, $P<0.0001)$. LH concentrations were significantly higher at the $10 \mathrm{~min}$ time point compared with the baseline $(P<0.05)$ and decreased throughout the remaining time points. There were no significant differences between nulliparous and multiparous rats at any time point $(F 4,84=0.18, P>0.05)$.

When $0.5 \mathrm{mg}$ naloxone $\mathrm{kg}^{-1}$ i.v. was administered on dioestrus II of the subsequent oestrous cycle, LH concentrations in the nulliparous and multiparous female rats once again differed significantly over time $(F 4,72=19.53$, $P<0.0001$ ), but the groups did not differ significantly from each other (F4,72 =1.38, $P>0.05$; Fig. $2 b)$. As with the $1 \mathrm{mg}$ $\mathrm{kg}^{-1}$ i.v. dose, the administration of $0.5 \mathrm{mg}$ naloxone $\mathrm{kg}^{-1}$ i.v. resulted in a maximal response at $10 \mathrm{~min}(P<0.05)$ followed by a gradual decline over the time period.

The advancing age of these rats combined with the lack of reproductive experience in the nulliparous group had a significant effect on oestrous cyclicity. More nulliparous females ( 9 of 15) displayed irregular oestrous cycles or were acyclic (Fisher's $P<0.0001$ ) at 8 months of age than were the

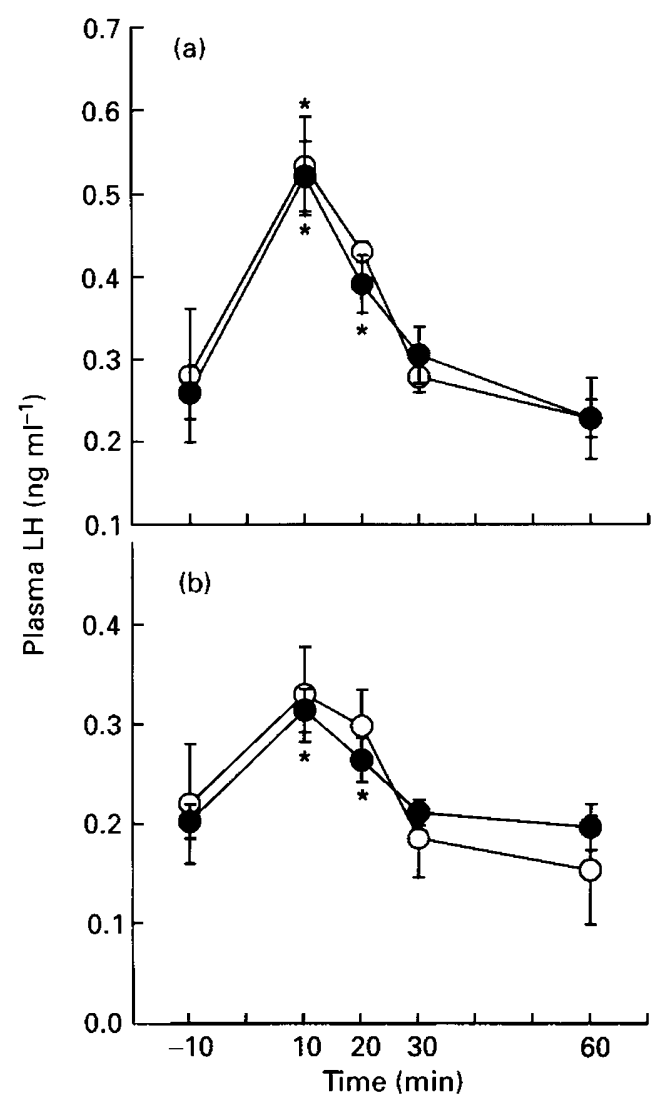

Fig. 2. Comparison of plasma concentrations of LH in nulliparous (O) and multiparous $(0)$ rats on dioestrus II after administration of naloxone at $1 \mathrm{mg} \mathrm{kg}^{-1}$ i.v. (a) ( $n=6$ and 17 , respectively), and on the subsequent oestrous cycle at a dose of $0.5 \mathrm{mg} \mathrm{kg}^{-1}$ i.v. (b) ( $n=4$ and 16 , respectively). No significant differences were found between the nulliparous and multiparous females, although naloxone treatments resulted in significant increases in $\mathrm{LH}$ versus baseline samples $\left({ }^{*} P<0.05\right)$

multiparous females ( 0 of 23$)$. This difference exemplifies the effect parity exerts on maintaining reproductive cyclicity.

\section{Experiment 3}

In the first part of this experiment plasma LH concentrations were measured in primiparous females after i.v. administration of four different doses of naloxone (Fig. 3) on day 8 of lactation. There was a significant main effect of time $(\mathrm{F} 5,110=7.95, P<0.0001)$; $\mathrm{LH}$ concentrations were significantly higher at the $10 \mathrm{~min}$ time point compared with the baseline after the 2,5 and $10 \mathrm{mg} \mathrm{kg}^{-1}$ i.v. doses of naloxone $(P<0.05)$. The $25 \mathrm{mg} \mathrm{kg}^{-1}$ i.v. dose did not significantly increase LH $(P>0.05)$. LH concentrations were significantly lower at $10 \mathrm{~min}$ after treatment with $25 \mathrm{mg}$ naloxone $\mathrm{kg}^{-1}$. The LH response to this naloxone dose was significantly lower than that of the 2 and $5 \mathrm{mg} \mathrm{kg}^{-1}$ doses.

In the second part of Expt 3, an examination of plasma $\mathrm{LH}$ concentrations collected on day 8 of lactation after $2.0 \mathrm{mg}$ naloxone $\mathrm{kg}^{-1}$ revealed that plasma LH concentrations differed over time in both primiparous and multiparous rats 


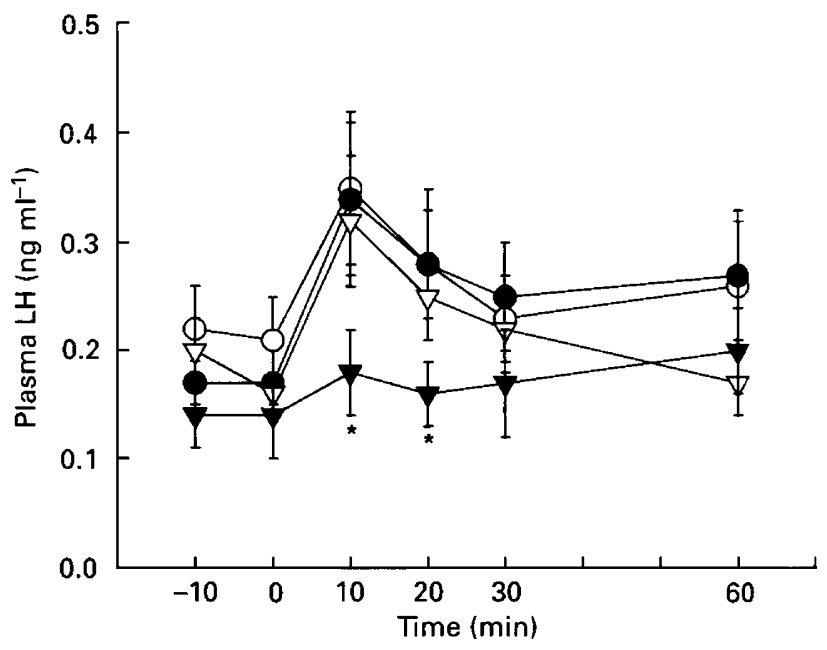

Fig. 3. Comparison of plasma concentrations of LH after administration of $2(\bigcirc), 5(\bullet), 10(\nabla)$, and $25(\nabla) \mathrm{mg}$ naloxone $\mathrm{kg}^{-1}$, i.v. in primiparous lactating rats. Plasma concentrations of $\mathrm{LH}$ during lactation increased significantly compared with baseline at the 10 min time point for the 2,5 , and $10 \mathrm{mg} \mathrm{kg}^{-1}$ doses only. ${ }^{*} P<0.05$ at the $10 \mathrm{~min}$ time point for $25 \mathrm{mg} \mathrm{kg}^{-1}$ compared with 2,5 and $10 \mathrm{mg}$ $\mathrm{kg}^{-1}$ doses, and at the 20 min time point compared with the 2 and $5 \mathrm{mg}$ $\mathrm{kg}^{-1}$ doses.

(F3,84 $=27.17, P<0.0001)$. Basal LH concentrations averaged about $0.17 \pm 0.03 \mathrm{ng} \mathrm{ml}^{-1}$ and increased to about $0.35 \pm 0.05 \mathrm{ng}$ $\mathrm{ml}^{-1}$ at the $10 \mathrm{~min}$ time point in both groups. The responses of these groups did not differ significantly from each other $(\mathrm{F} 3,84=0.11, P>0.05)$. The stimulatory effect of naloxone on $\mathrm{LH}$ secretion was maximal at $10 \mathrm{~min}$ and then diminished over time in both groups at approximately the same rate $(P<0.05)$.

On day 10 of lactation females received either $10 \mathrm{mg} \mathrm{kg}^{-1}$ or $0.5 \mathrm{mg} \mathrm{kg}^{-1}$ naloxone i.v. The $10 \mathrm{mg}$ naloxone $\mathrm{kg}^{-1}$ resulted in increases in LH concentrations for both primiparous and multiparous rats which differed over time $(\mathrm{F} 3,42=16.1, P<$ 0.0001 ). Baseline $\mathrm{LH}$ concentrations in primiparous rats averaged about $0.18 \pm 0.05 \mathrm{ng} \mathrm{ml}^{-1}$ and increased to about $0.34 \pm 0.08 \mathrm{ng} \mathrm{ml}^{-1}$ at the $10 \mathrm{~min}$ time point, while basal $\mathrm{LH}$ concentrations in the multiparous rats averaged $0.17 \pm 0.03$ $\mathrm{ng} \mathrm{ml} l^{-1}$ and increased to $0.27 \pm 0.04 \mathrm{ng} \mathrm{ml}^{-1}$ at $10 \mathrm{~min}$. The LH responses of these rats did not differ from each other ( $\mathrm{F} 3,42=0.85, P>0.05$ ). The overall trend, therefore, was a maximal $\mathrm{LH}$ response to naloxone administration at $10 \mathrm{~min}$ $(P<0.05)$ followed by an equivalent and gradual decline over the duration of sampling. In contrast, $0.5 \mathrm{mg}$ naloxone $\mathrm{kg}^{-1}$ i.v. (Fig. 4) resulted in LH concentrations that differed over time $(\mathrm{F} 3,30=9.54, P<0.001)$ and were significantly different between the primiparous and multiparous female rats at all time points, including the baseline time point $(\mathrm{F} 1,30=17.1, P<0.01)$. Difference scores were calculated (see statistical methods) and compared to determine whether the difference at all other time points was due to the significant difference in baseline. The statistical difference found between the primiparous and multiparous females after naloxone treatment was not due to differences in baseline $\mathrm{LH}$ concentrations. At the $10 \mathrm{~min}$ sampling time, LH concentrations in multiparous females had increased

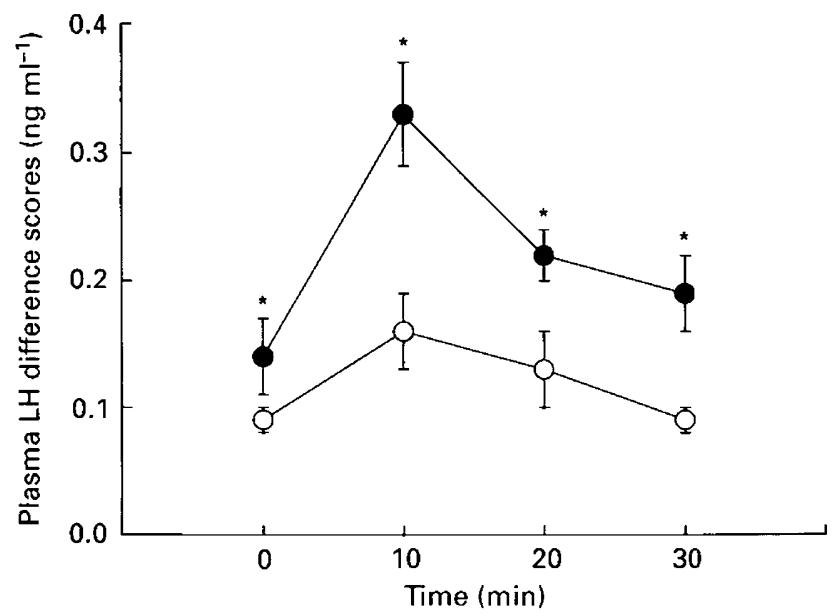

Fig. 4. Comparison of plasma concentrations of LH after administration of naloxone $\left(0.5 \mathrm{mg} \mathrm{kg}^{-1}\right.$ i.v. $)$ to primiparous $(\mathrm{O}$; $n=5)$ and multiparous $(\varphi ; n=7)$ females on day 10 of lactation. Multiparous females had significantly higher plasma concentrations of $\mathrm{LH}$ after administration of naloxone $\left(0.5 \mathrm{mg} \mathrm{kg}^{-1}\right.$ i.v. $)$ than did primiparous females. ${ }^{*} P<0.05$ compared with primiparous rats.

$0.175 \mathrm{ng} \mathrm{ml}^{-1}$ from baseline concentrations, while LH concentrations only increased by $0.075 \mathrm{ng} \mathrm{ml}^{-1}$ in primiparous mothers $(P<0.05)$. Comparable differences persisted at 20 and $30 \mathrm{~min}(P<0.05)$. Thus, the overall trend was increases in LH in response to naloxone, increases which were significantly larger in multiparous females and which declined gradually over time.

\section{Discussion}

The overall hypothesis in this study was that with increases in reproductive experience, that is, pregnancy and lactation, rats would become less sensitive to the effects of EOP and thus less sensitive to the effects of the nonspecific opioid antagonist, naloxone. In the first part of Expt 1 the effects of two naloxone doses $\left(1 \mathrm{mg} \mathrm{kg}^{-1}\right.$ and $10 \mathrm{mg} \mathrm{kg}^{-1}$ i.v. $)$ on $\mathrm{LH}$ secretion were measured in nulliparous rats. Naloxone at 1 $\mathrm{mg} \mathrm{kg}^{-1}$ i.v. which stimulated an increase in LH release within $10 \mathrm{~min}$ was then used to compare the LH response of age-matched, cyclic nulliparous and primiparous female rats. No significant difference in the $\mathrm{LH}$ response to naloxone was found between these groups, indicating that opioid regulation of LH may not be altered by prior reproductive experience. One explanation for these findings is that this dose of naloxone may have been too high to detect differences in opioid sensitivity between these groups, for example it may have inhibited the action of the EOP equally in nulliparous and primiparous cyclic female rats. Future studies will be necessary to examine adequately the effect lower doses of naloxone might have in detecting whether there are differences in opioid sensitivity in rats as a function of different numbers of births. Alternatively, the difference of a single parity between nulliparous and primiparous females 
may not be great enough to influence the EOP system sufficiently to produce a significant difference in LH release, in contrast to the differential response seen with regard to prolactin release and maternal behaviour (Mann and Bridges, 1992). It is also possible that changes in opioid sensitivity produced by prior reproductive experience are not uniformly evident across all stages of the oestrous cycle. Although we did not detect changes in opioid regulation of $\mathrm{LH}$ on dioestrus II, an examination of $\mathrm{LH}$ responsiveness on other days of the oestrous cycle, for example proestrus, or under a different hormonal background, that is oestrogen dominance, might allow for detection of differences.

Increasing the amount of prior reproductive experience from one to three litters in the second experiment also did not significantly affect the LH responses of the nonlactating, multiparous (three births) female rats to naloxone at a dose of either $1 \mathrm{mg} \mathrm{kg}^{-1}$ or $0.5 \mathrm{mg} \mathrm{kg}^{-1}$ i.v. on dioestrus II of the oestrous cycle. One complication of this study was that animals were 8 to 9 months of age at the time of sampling. By this age many of the age-matched, nulliparous female rats had entered a state of persistent vaginal oestrus prior to sampling. Hence, the actual number of cyclic, nulliparous animals used was low. It is possible that differences between groups might have been found had the sample sizes been larger. The phenomenon of decreased cyclicity with age in nulliparous animals confirms the earlier results of Matt et al. (1987). In rats, multiparous animals continue to exhibit normal oestrous cycles into middle age, whereas few nulliparous rats display 4 or 5 day oestrous cycles (Matt et al., 1987).

The possibility was also investigated that another physiological state, that is, lactation, may provide an alternative model to assess the effects of reproductive experience on opioid regulation of LH. Earlier studies in rats established that throughout most of early to mid-lactation plasma LH concentrations are suppressed (Smith and Neill, 1977), primarily as a consequence of the suckling stimuli provided by the pups (McCann et al., 1967). Hence, in the present study, basal LH concentrations prior to naloxone treatments were quite low. In the third experiment, on day 8 of lactation age-matched, primiparous and multiparous (second litter) females had comparable LH responses to $2 \mathrm{mg}$ naloxone $\mathrm{kg}^{-1}$. In contrast, on day 10 of lactation, at $0.5 \mathrm{mg}$ naloxone $\mathrm{kg}^{-1}$, a significant difference emerged between primiparous and multiparous animals at every time point, including baseline concentrations. Subsequent analysis using difference scores likewise revealed that at the $10 \mathrm{~min}$ sampling time point multiparous females displayed a greater LH response to naloxone than did primiparous dams. The reason for the difference in baseline $\mathrm{LH}$ values between the $0.5 \mathrm{mg} \mathrm{kg}^{-1}$ treatment groups is unknown. However, it may in part reflect the limited sample size in animals given this dose of naloxone.

The finding that day 10 multiparous females are more sensitive to low doses of naloxone than are primiparous dams is in opposition to our initial hypothesis that reproductive experience renders females less sensitive to opioid regulation. Although this difference appears to be limited to a single low dose of naloxone, one possible explanation of this finding is that the dose-response curve to the opiate antagonist is bell-shaped and shifts to the left in multiparous animals so that at lower doses naloxone stimulates $\mathrm{LH}$ secretion more readily, while at high naloxone doses LH is more likely to be inhibited. Shifts in opiate responsiveness and concentrations of opiate receptors in the medial preoptic area have been demonstrated in reproductively experienced lactating rats (Bridges and Hammer, 1992; Mann and Bridges, 1992). In fact, the concentrations of $\mu$-opiate receptors is greater in day 12 multiparous lactating rats than in age-matched, primiparous controls (Bridges and Hammer, 1992). Might similar changes in $\mu$-opiate receptor or other opiate receptor numbers or occupancy account for this shift in naloxone-induced $\mathrm{LH}$ secretion? Further studies are needed to clarify the relationships between opiate antagonist dose, reproductive experience, and neural receptor densities.

The lack of an $\mathrm{LH}$ response in primiparous lactating rats administered $25 \mathrm{mg}$ naloxone $\mathrm{kg}^{-1}$ in Expt 3 was unexpected, since the three lower doses of naloxone stimulated increases in plasma LH. This lack of LH stimulation to this high dose of naloxone may be a reflection of the superpharmacological treatment. This $25 \mathrm{mg} \mathrm{kg}^{-1}$ dose of naloxone is higher than those previously used to access opiate regulation of $\mathrm{LH}$ secretion, and thus may functionally shut down opioid regulation of LH. It would be of interest to examine the central actions of this high naloxone dose to see how it affects opiate receptors and endogenous opioid synthesis. Finally, while we used plasma LH release as our dependent variable in these studies, it may also be worthwhile to examine pituitary LH stores and message in reproductively experienced and naive females to determine whether the processing of pituitary LH and not just its release may be affected by prior pregnancies and lactations. It is possible that differences in pituitary LH synthesis and storage occur that may not be reflected in plasma LH concentrations.

In summary, our results indicate that prior reproductive experience prolongs normal oestrous cyclicity and appears to increase the magnitude of the LH response of lactating, multiparous females to low doses of opiate antagonists. During lactation, a change in opioid regulation of $\mathrm{LH}$ in response to maximal doses of naloxone was not evident during the oestrous cycle of reproductively experienced animals at the doses of naloxone examined. Further studies, however, are needed to determine how a female's past reproductive experience may affect her subsequent neurochemical state, since it would influence, for example, the nature and dose of drugs that should be administered. Moreover, shifts in neurochemical sensitivity to substances that regulate $\mathrm{GnRH}$ and $\mathrm{LH}$ after prior pregnancies and lactations would be expected to affect reproductive ageing, influencing the duration of fertility in adulthood.

The authors would like to thank J. Coppeta for her technical assistance, data analysis and data preparation and B. Henriquez for her help with the LH RIA. They would also like to express appreciation to $\mathrm{B}$. Rubin for helpful suggestions in preparation of this manuscript. This research was supported by a NIH grant (HD29782) awarded to RS Bridges and an NIH short-term training grant (T35 DK07635) awarded to Tufts University School of Veterinary Medicine (RM Hopwood). 


\section{References}

Blank MS, Panerai AE and Friesen HG (1979) Opioid peptides modulate luteinizing hormone secretion during sexual maturation Science 203 1129-1131

Blank MS, Mann DR, Daugherty DT, Sridiran R and Murphy JR (1986) Central, stereoselective receptors mediate the acute effects of opiate antagonists on luteinizing hormone secretion Life Sciences $391493-1499$

Bridges RS and Hammer RP, Jr (1992) Parity-associated alterations in the medial preoptic opiate receptors in female rats Brain Research 578 269-274

Chiba A, Akema T, Nagami Y, Kimura F and Toyoda J (1997) Differential inhibition of NMDA- and naloxone-induced LH release by NMDA receptor antagonist and $\mathrm{CRH}$ in ovariectomized estrogen-primed rats Neuroendocrinology $65141-146$

Cicero TJ, Wilcox CE, Bell RD and Meyer ER (1980) Naloxone-induced increases in serum luteinizing hormone in the male: mechanisms of action Journal of Pharmacology and Experimental Therapeutics 212 573-578

Dondi D, Maiigi R, Panerai AE, Piva F and Limonta P (1991) Hypothalamic opiatergic tone during pregnancy, parturition and lactation in the rat Neuroendocrinology 53 460-466

Gabriel SM, Simpkins JW and Kalra SP (1983) Modulation of endogenous opioid influence on luteinizing hormone secretion by progesterone and estrogen Endocrinology 113 1806-1811

Kinsley CH and Bridges RS (1988) Parity-associated reductions in behavioral sensitivity to opiates Biology of Reproduction $39270-278$
Mann PE and Bridges RS (1992) Neural and endocrine sensitivities to opioids decline as a function of multiparity in the rat Brain Research 580 241-248

Matt DW, Sarver PL and Lu JK (1987) Relation of parity and estrous cyclicity to the biology of pregnancy in aging female rats Biology of Reproduction 37 421-430

McCann SM, Graves T and Taleisnik S (1967) The effect of lactation on plasma LH Endocrinology 68 873-874

Numan M (1990) Neural control of maternal behavior. In Mammalian Parenting: Biochemical, Neurobiological and Behavioral Determinants pp 231-259 Eds NA Krasnegor and RS Bridges. Oxford University Press, Oxford

Rubin BS, Elkind-Hirsch K and Bridges RS (1985) Hypothalamic LHRH in aging rats: effects of ovariectomy and steroid placement Neurobiology of Aging 6 309-315

Selmanoff $\mathbf{M}$ and Gregerson KA (1986) Suckling-induced prolactin release is suppressed by naloxone and stimulated by beta-endorphin Neuroendocrinology 42 255-259

Smith MS and Neill JD (1977) Inhibition of gonadotropin secretion during lactation in the rat: relative contribution of suckling and ovarian steroids Biology of Reproduction 17 255-261

Weiner RI, Findell PR and Kordon C (1988) Role of classic and peptide neuromediators in the neuroendocrine regulation of $\mathrm{LH}$ and prolactin. In The Physiology of Reproduction pp 1235-1281. Eds E Knobil and JD Neill. Raven Press, New York 